\title{
PHYSICAL THERAPY FOR EMERGENCY ABDOMINAL SURGERY: STATE OF THE PROBLEM IN UKRAINE
}

\author{
Hanna Hula \\ Ph.D., Assistant Professor at the Department of Physical Therapy and Occupational Therapy, \\ Ivan Bobersky Lviv State University of Physical Culture, Ukraine \\ e-mail: ganna.gula@likar.medcenter.lviv.ua,orcid.org/0000-0001-8636-1111
}

\section{Olha Bas}

Ph.D., Assistant Professor at the Department of Physical Therapy and Occupational Therapy, Ivan Bobersky Lviv State University of Physical Culture, Ukraine e-mail: bas_olia@ukr.net,orcid.org/0000-0003-2328-3093

\section{Summary}

For today there are significant medical advances in surgical treatment of emergency abdominal pathology and surgical techniques. However, the place of physical therapy in guidelines of acute abdominal pathology complex treatment remains insufficiently described in the specialized literature, and its significance in clinical practice underestimated. Emergency abdominal surgical pathology still remains a significant proportion of all surgical diseases, whereas mortality and postoperative complications remain considerably high. Surgical interventions in this cohort belong to the high-risk category in the cases of old age, poor general health with the limited cardiorespiratory reserve, low physical strength and obesity.

Among other reasons of this study importance, there are insufficient clinical guidelines and misunderstanding of physical therapy impact on treatment outcome, such as mortality, frequency and type of postoperative morbidity, duration of in hospital stay, quality of life and rate of physical recovery.

Only moderate quantity of thorough studies is available, concerning major urgent abdominal pathology complex treatment which comprehends surgical, anesthesia, laboratory, imaging, physiotherapy and nutritional support expertise. However, current evidence from trials remains obscure due to absence of clearly defined, standardized physiotherapy interventions, which limits the comparison in the treatment outcomes assessment.

Currently in Ukraine there are no standards of physical therapy in clinical protocol of emergency abdominal surgical pathology. Consequently, there is a necessity for theoretic and practical justification of physical therapy as an important component of comprehensive treatment in the case of emergency abdominal surgical pathology.

Keywords: postoperative rehabilitation, guidelines in emergency abdominal surgical pathology.

DOI: https://doi.org/10.23856/4629

\section{Introduction}

Emergency abdominal pathology (EAP) compose a significant part of all surgical diseases, at the same time, indicators of mortality and postoperative complications remain significant (Bereznyczkyy et al., 2015: 73; Burcharth et al., 2019: 467; Fomin et al., 2018: 9; Rose et al., 2015: 13). According to the data from the Center for Medical Statistics of the Ministry 
of Health of Ukraine, over the past 20 years the total number of operations on the digestive system and abdominal cavity ranged from 61.9 to 73.5 per 10 thousand of population, and in 2018 amounted to 64.95 per 10 thousand of population. At the same time, postoperative mortality was in the range of $1.79 \%-2.67 \%$, in 2018 it was $1.89 \%$ (5173 persons). The rate of EAP decreased annually - from 39.1 (2000) to 27.1 (2017) per 10 thousand of population, and in 2018 it was 25.8; at the same time, postoperative mortality in 2018 amounted to $1.34 \%$ (1456 persons), compared to $1.17 \%-1.98 \%$ in previous years. Postoperative mortality rate in delayed hospital admission (later than 24 hours from the onset of the disease) remains significant and is $2.32 \%$, with an interval of $2.12 \%-3.92 \%$ (Digest of public institution "Medical Statistics Center of the Ministry of Health of Ukraine» "Indicators of public health", 2000-2018).

The necessity to further improve the quality of emergency care in EAP is admitted worldwide (Burcharth et al., 2019: 468; Howes et al., 2015: 1027; McIsaac et al., 2017: 1653; Stephens et al., 2018: 142). Surgery for EAP is high risk, particularly in the presence of such factors as old age, poor general health, low physical strength, and obesity. (Abbott et al., 2017: 249; Barberan-Garcia et al., 2018: 51; Nally et al., 2019: 7; Saunders et al., 2012: 368). Owing to the success of modern surgery and anesthesiology, it is now possible to perform increasingly complex interventions in patients with complex comorbidities, which a few years ago were considered inoperable. At the same time, patients with limited cardiorespiratory reserve have a higher risk of postoperative complications and mortality (Tengberg et al., 2017: 464). According to researchers, the rate of postoperative mortality is significantly dependent on postoperative complications development in the first 30 days after surgery (Al-Temimi et al., 2012: 510; Tolstrup et al., 2016: 621). Even in the absence of such complications, the general physical condition and quality of life disimproved by 20-40\% (Lawrence et al., 2004: 763).

A significant number of researches are devoted to the issues of pathogenesis, diagnostics, tactics of surgical treatment of EAP and solutions of surgical intervention methods (McIsaac et al., 2017: 1656; Møller et al., 2011: 809; Rose et al., 2015: 19; Stephens et al., 2018: 142). Multicenter, national and international studies of EAP treatment results have shown their dependence on the patient's condition and the organization of surgical care (Green et al., 2013: 221; Shahan et al., 2015: 116; Stephens et al., 2018: 142). On the basis of such researches, clinical guidelines of medical care at EAP are formed and the corresponding audit is carried out (Barberan-Garcia et al., 2018: 52; Broughton et al., 2017: 894; Order № 297 of the Ministry of Health of Ukraine dated Apr 2, 2010 "On approval of standards and clinical protocols for the provision of medical care in the specialty "Surgery»"; Saunders et al., 2012: 371).

The researchers work on the development and improvement of clinical guidelines for EAP is focused mainly on the improvement of surgical techniques, methods of adequate analgesia, perioperative support and postoperative conservative therapy (Fomin et al., 2018: 52; Barberan-Garcia et al., 2018: 55). Isolated reports of the implementation of a comprehensive perioperative algorithm for the treatment of major EAP appeared only in recent years, which includes surgical, anesthetic, intensive care, diagnostic, radiation, physiotherapy and nutritional support (Burcharth et al., 2019: 468; Lavallée et al., 2017: 142; Tengberg et al., 2017: 467). At the same time, the dependence of effective implementation of the multidisciplinary approach on proper team cooperation in several departments and specialties is highlighted (Gramlich et al., 2017: 67; Wolk et al., 2016: 356).

At the same, the problem of physical therapy (FT) in the system of EAP treatment remains insufficiently studied and weakly covered by researches. In particular, among the reasons for this are the lack of its standard and insufficiently studied impact on treatment outcomes. So, importance of FT for EAP treatment is still underestimated (Burcharth et al., 2019: 477; 
Kamarajah et al., 2019: 548; Ljungqvist et al., 2017: 292; Visioni et al., 2018: 64). Standards of EAP treatment needed to be reoriented from the classical model of medical care due to surgical disease to an active approach, that will allow the patient to become an active participant in this process (Alam et al., 2019: 2674).

The aim of this study - to generalize the state of theoretical and practical solution of the problem of FT in the EAP treatment system.

Materials and methods of research: analysis of the literature and current regulations which governing medical care in EAP.

\section{Research results and their discussion}

Modern studies and meta-analyzes of emergency abdominal surgical pathology treatment results (general and postoperative mortality, postoperative pulmonary and cardiac complications, duration of inpatient treatment, etc.), that was conducted using random effects models and by implementing a multidisciplinary protocol, showed the positive effect of FT in patients who underwent major abdominal surgery (Burcharth et al., 2019: 476; Kamarajah et al., 2019: 549). Some studies indicate the importance of early FT as an integral part of the treatment process after surgical treatment of EAP, directly with intensive care and drug therapy (Pedziwiatr et al., 2015: 80). At the same time, the current evidence of randomized trials remains weak due to the lack of a coordinated system of FT in such patients after surgery for EAP, which limits the assessment of treatment outcomes (Burcharth et al., 2019: 477; Gramlich et al., 2017: 67).

A team of Australian scientists is currently conducting a clinical multicenter, double-blind, placebo-controlled, randomized study of the effects of an improved FT-package compared to the standard in patients after emergency abdominal surgery in three clinics with different levels of care (Boden et al., 2018: 29). Patients receive or standard FT (training, one session of training breathing exercises, and daily early physical activity for 15 minutes: 'talk, walk \& breathe'), either an improved package of FT (training, staff-controlled breathing exercises twice a day, and 30 minutes daily early physical rehabilitation for at least five postoperative days). According to standardized diagnostic criteria (Melbourne Group Score, Melbourne Group Score) the effect of FT primarily on the incidence of respiratory complications during the first 14 postoperative days will be assessed, as well as the probable effect of FT on postoperative intestinal paresis, duration and cost of inpatient treatment, postoperative 90-day and 1-year mortality, the rate of physical and functional recovery and quality of life.

In keeping with the Law of Ukraine "Fundamentals of the legislation of Ukraine on health care", the concept of "health" is defined as a state of complete physical, mental and social well-being, not only the absence of disease and physical defects. One of the principles of health care in Ukraine there is a focus on modern standards of health and medical care, a combination of national traditions and achievements with world experience. However, in Ukraine until now there is no standard of FT in the EAP treatment protocol (Order № 297 of the Ministry of Health of Ukraine dated Apr 2, 2010 "On approval of standards and clinical protocols for the provision of medical care in the specialty "Surgery»"; Order № 751 of the Ministry of Health of Ukraine dated Sep 28, 2012 "About creation and introduction of medical and technological documents on standardization of medical care in system of the Ministry of Health of Ukraine”, with amendments due to Order № 1422 of the Ministry of Health of Ukraine dated Dec 29, 2016). Consequently, as a rule, modern methods of FT as a component of EAP complex treatment are insufficiently used in medical institutions (Grygoryev et al., 2008: 99). Only in 2018, 
the doctor's guide "Emergency surgery of the abdominal cavity (standards of organization and professionally oriented algorithms of medical care)" in some models of clinical cases of a unified protocol for diagnostic and therapeutic care in terms of postoperative treatment indicates subsection "therapeutic gymnastics, physiotherapy testimony", however, without any detailed instructions (Fomin et al., 2018: 322).

At the end of 2020, a decisive step in the development of rehabilitation in Ukraine was carried out - the Law of Ukraine "On Rehabilitation in Health Care" was passed, which defines the legal, organizational and economic principles of rehabilitation of persons with everyday disabilities in the field of health care. In particular, this law defines FT as a process of ensuring the development, maximum recovery and maintenance of motor and functional capacity of persons with limitations of daily functioning or such actions, in which such limitations may arise. The Law emphasizes the application of evidence-based rehabilitation principles. Also, to comply with this Law, protocols for the provision of rehabilitation care should be developed. As of today, the first and only protocol on implementation of the Law of Ukraine "On Rehabilitation in Health Care" is the "Protocol for the provision of rehabilitation care to patients with coronavirus disease (COVID-19) and convalescents", approved by the Ministry of Health of Ukraine on April 20, 2021.

Summarizing of the conducted analysis results, there is reason to affirm that the problem of FT in EAP treatment is not solved, and the available theoretical material and practical experience is not implemented in the health care system of Ukraine. There are still a number of contradictions:

- between the further improvement of the quality of emergency medical care for patients with EAP and the neglect of the deterioration of the physical condition and quality of life of patients due to acute surgical disease and emergency intervention;

- between a significant number of patients hospitalized with EAP and the lack of a well-established, science-based concepts of FT as a component of emergency surgical care;

- between the need to improve the results of EAP treatment (reduction of overall and postoperative mortality, including in case of late hospitalization, reduction of postoperative complications, duration of inpatient treatment, etc.) and the lack of FT methodology in the treatment system of EAP;

- between recognizing the need for a multidisciplinary approach in the treatment of EAP and ignoring the FT program of such patients by scientists and clinicians;

- between the existing legislative and regulatory protocols for the treatment of EAP approved by the Ministry of Health of Ukraine and the absence of the FT standard in these protocols;

- between the theoretical recognition of the need to use FT in EAP treatment and undeveloped mechanisms for its implementation into the work of health care institutions of Ukraine.

\section{Conclusions and prospects for further research}

In view of the above, there is an actual scientific and applied problem of theoretical and methodological substantiation of FT as an integrated component of EAP complex treatment system. The tasks to be solved for its solution are: generalization of the state of theoretical and practical solutions in treatment of urgent abdominal surgical pathology; definition of the problem field, structure, content and organization of FT in its treatment; establishing the content and implementation of FT standards in the treatment of EAP, implemented in the health care system of different countries; identification of patterns, establishment of principles and methodological 
provisions, development of the concept, determination of application criteria, experimental verification of the effectiveness of the implementation provisions of the concept of FT in EAP complex treatment system.

\section{References}

Abbott, T. E. F., Fowler, A. J., Dobbs, T. D, Harrison, E. M., Gillies, M. A., Pearse, R. M. (2017). Frequency of surgical treatment and related hospital procedures in the UK: a national ecological study using hospital episode statistics. Br J Anaesth.

Alam, R., Montanez, J., Law, S., Lee, L., Pecorelli, N., Watanabe, Y., et al. (2019). Development of a conceptual framework of recovery after abdominal surgery. Surg Endosc.

Al-Temimi, M. H., Griffee, M., Enniss, T. M., Preston, R., Vargo, D., Overton, S., et al. (2012). When is death inevitable after emergency laparotomy? Analysis of the American College of Surgeons National Surgical Quality Improvement Program database. J Am Coll Surg.

Barberan-Garcia, A., Ubré, M., Roca, J., Lacy, A. M., Burgos, F., Risco, R., et al. (2018). Personalised prehabilitation in high-risk patients undergoing elective major abdominal surgery: $a$ randomized blinded controlled trial. Ann Surg.

Bereznyczkyy, Y. S., Yaroshenko K. O. (2015). Suchasni organizacijni ta taktychni pytannya likuvannya shlunkovo-kyshkovyh krovotech [Modern organizational and tactical issues in treatment of gastrointestinal bleeding]. Acta medica Leopoliensia. [in Ukrainian]

Boden, I., Sullivan, K., Hackett, C., Winzer, B., Lane, R., McKinnon, M., et al. (2018). ICEAGE (Incidence of Complications following Emergency Abdominal surgery: Get Exercising): study protocol of a pragmatic, multicentre, randomised controlled trial testing physiotherapy for the prevention of complications and improved physical recovery after emergency abdominal surgery. World J Emerg Surg.

Broughton, K. J., Aldridge, O., Pradhan, S., Aitken, R. J. (2017). The Perth emergency laparotomy audit. ANZ J Surg.

Burcharth, J., Abdulhady, L., Danker, J., Ekeloef, S., Jørgensen, T., Lauridsen, H., et al. (2019). Implementation of a multidisciplinary perioperative protocol in major emergency abdominal surgery. Eur J Trauma Emerg Surg.

Dovidnyk DZ "Centr medychnoyi statystyky MOZ Ukrayiny" "Pokaznyky zdorovya naselennya", 2000-2018rr. [Digest of public institution "Medical Statistics Center of the Ministry of Health of Ukraine» "Indicators of public health", 2000-2018]. Kyiv. [in Ukrainian]

Fomin, P. D., Usenko, O. Y., Bereznyczkyy, Y. S., et al. (2018). Nevidkladna xirurgiya organiv cherevnoyi porozhnyny (standarty organizaciyi ta profesijno oriyentovani algorytmy nadannya medychnoyi dopomogy) [Emergency abdominal surgery (standards of organization and professionally oriented algorithms of medical care)]. Kyiv: Zdorovya Ukrayiny. [in Ukrainian]

Gramlich, L. M., Sheppard, C. E., Wasylak, T., Gilmour, L. E., Ljungqvist, O., Basualdo-Hammond, C., et al. (2017). Implementation of enhanced recovery after surgery: a strategy to transform surgical care across a health system. Implement Sci.

Green, G., Shaikh, I., Fernandes, R., Wegstapel, H. (2013). Emergency laparotomy in octogenarians: a 5-year study of morbidity and mortality. World J Gastrointest Surg.

Grygoryev, A. J., Balan, M. M., Raczul, A. B. (2008). Encyklopediya fizychnoyi reabilitaciyi. Naukovo-metodychne vydannya. Kyiv: Imeks-LTD [in Ukrainian]

Howes, T. E., Cook, T. M., Corrigan, L. J., Dalton, S. J., Richards, S. K., Peden, C. J. (2015). Postoperative morbidity survey, mortality and length of stay following emergency laparotomy. Anaesthesia. 
Kamarajah, S. K., Bundred, J., Weblin, J., Tan, B. H. L. (2019). Critical appraisal on the impact of preoperative rehabilitation and outcomes after major abdominal and cardiothoracic surgery: A systematic review and meta-analysis. Surgery.

Lavallée, J. F., Gray, T. A., Dumville, J., Russell, W., Cullum, N. (2017). The effects of care bundles on patient outcomes: a systematic review and meta-analysis. Implement Sci.

Lawrence, V. A., Hazuda, H. P., Cornell, J. E., Pederson, T., Bradshaw, P. T., Mulrow, C. D., et al. (2004). Functional independence after major abdominal surgery in the elderly. $J$ Am Coll Surg.

Ljungqvist, O., Scott, M., Fearon, K. C. (2017). Enhanced recovery after surgery: a review. JAMA Surg.

McIsaac, D. I., Moloo, H., Bryson, G. L., van Walraven, C. (2017). The association of frailty with outcomes and resource use after emergency general surgery: a population-based cohort study. Anesth Analg.

Møller, M. H., Adamsen, S., Thomsen, R. W., Møller, A. M. (2011). Multicentre trial of a perioperative protocol to reduce mortality in patients with peptic ulcer perforation. Br J Surg.

Nakaz № 1422 MOZ Ukrayini vid 29.12.2016 r. "Pro vnesennya zmin do nakazu Ministerstva okhoroni zdorov'ya Ukrayini vid 28 veresnya 2012 roku № 751» [Order № 1422 of the Ministry of Health of Ukraine dated Dec 29, 2016 "On amendments to the order of the Ministry of Health of Ukraine from Sep 28, 2012 № 751»]. Kyiv. [in Ukrainian]

Nakaz № 297 MOZ Ukrayini vid 02.04.2010r. "Pro zatverdzhennya standartiv ta klinichnikh protokoliv nadannya medichnoyi dopomogi zi spetsialnosti "Khirurgiya"» [Order № 297 of the Ministry of Health of Ukraine dated Apr 2, 2010 "On approval of standards and clinical protocols for the provision of medical care in the specialty "Surgery»"]. Kyiv. [in Ukrainian]

Nakaz № 751 MOZ Ukrayini vid 28.09.2012r. «Pro stvorennya ta vprovadzhennya mediko-tekhnologichnikh dokumentiv zi standartizatsiyi medichnoyi dopomogi v sistemi Ministerstva okhoroni zdorov'ya Ukrayini» [Order № 751 of the Ministry of Health of Ukraine dated Sep 28, 2012 "About creation and introduction of medical and technological documents on standardization of medical care in system of the Ministry of Health of Ukraine”]. Kyiv. [in Ukrainian] Nally, D. M., Sørensen, J., Valentelyte, G., Hammond, L., McNamara, D., Kavanagh, D. O., et al. (2019). Volume and in-hospital mortality after emergency abdominal surgery: a national population-based study. BMJ Open.

Pedziwiatr, M., Kisialeuski, M., Wierdak, M., Stanek, M., Natkaniec, M., Matłok, M., et al. (2015). Early implementation of enhanced recovery after surgery (ERAS $\left.{ }^{\circledR}\right)$ protocol - compliance improves outcomes: a prospective cohort study. Int J Surg.

Rose, J., Weiser, T. G., Hider, P., Wilson, L., Gruen, R. L., Bickler, S. W. (2015). Estimated need for surgery worldwide based on prevalence of diseases: a modelling strategy for the WHO Global Health Estimate. Lancet Glob Health.

Saunders, D. I., Murray, D., Pichel, A. C., Varley, S., Peden, C. J.; UK Emergency Laparotomy Network. (2012). Variations in mortality after emergency laparotomy: the first report of the UK emergency laparotomy network. Br J Anaesth.

Shahan, C. P., Bell, T., Paulus, E., Zarzaur, B. L. (2015). Emergency general surgery outcomes at safety net hospitals. J Surg Res.

Stephens, T. J., Peden, C. J., Pearse, R. M., Shaw, S. E., Abbott, T. E. F., Jones, E. L., et al. (2018). The Improving care at scale: process evaluation of a multi-component quality improvement intervention to reduce mortality after emergency abdominal surgery (EPOCH trial). Implement Sci. 
Tengberg, L. T., Bay-Nielsen, M., Bisgaard, T., Cihoric, M., Lauritsen, M. L., Foss, N. B.; AHA study group. (2017). Multidisciplinary perioperative protocol in patients undergoing acute high-risk abdominal surgery. Br J Surg.

Tengberg, L. T., Bay-Nielsen, M., Bisgaard, T., Cihoric, M., Lauritsen, M. L., Foss, N. B.; AHA study group. (2017). Multidisciplinary perioperative protocol in patients undergoing acute high-risk abdominal surgery. Br J Surg.

Tolstrup, M. B., Watt, S. K., Gögenur, I. (2016). Morbidity and mortality rates after emergency abdominal surgery: an analysis of 4346 patients scheduled for emergency laparotomy or laparoscopy. Langenbeck's Arch Surg.

Visioni, A., Shah, R., Gabriel, E., Attwood, K., Kukar, M., Nurkin, S. (2018). Enhanced recovery after surgery for noncolorectal surgery? A systematic review and meta-analysis of major abdominal surgery. Ann Surg.

Wolk, S., Distler, M., Müssle, B., Söthje, S., Weitz, J., Welsch, T. (2016). Adherence to ERAS elements in major visceral surgery - an observational pilot study. Langenbeck's Arch Surg. 